\title{
Correlates of the preoperative level of CA125 at presentation of ovarian cancer
}

\section{Citation}

Cramer, Daniel W., Allison F. Vitonis, William R. Welch, Kathryn L. Terry, Annekathryn Goodman, Bo R. Rueda, and Ross S. Berkowitz. 2010. "Correlates of the Preoperative Level of CA125 at Presentation of Ovarian Cancer." Gynecologic Oncology 119 (3) (December): 462-468. doi:10.1016/j.ygyno.2010.08.028.

\section{Published Version}

doi:10.1016/j.ygyno.2010.08.028

\section{Permanent link}

http://nrs.harvard.edu/urn-3:HUL.InstRepos:27332765

\section{Terms of Use}

This article was downloaded from Harvard University's DASH repository, and is made available under the terms and conditions applicable to Other Posted Material, as set forth at http:// nrs.harvard.edu/urn-3:HUL.InstRepos:dash.current.terms-of-use\#LAA

\section{Share Your Story}

The Harvard community has made this article openly available.

Please share how this access benefits you. Submit a story.

\section{Accessibility}


Published in final edited form as:

Gynecol Oncol. 2010 December ; 119(3): 462-468. doi:10.1016/j.ygyno.2010.08.028.

\title{
Correlates of the pre-operative level of CA125 at presentation of ovarian cancer
}

\author{
Daniel W. Cramer ${ }^{1}$, Allison F. Vitonis ${ }^{1}$, William R. Welch ${ }^{2}$, Kathryn L. Terry ${ }^{1}$, Annekathryn \\ Goodman $^{3}$, Bo R. Rueda ${ }^{4}$, and Ross S. Berkowitz ${ }^{1}$ \\ Daniel W. Cramer: dcramer@partners.org; Allison F. Vitonis: avitonis@partners.org; William R. Welch: \\ wrwelch@partners.org; Kathryn L. Terry: kterry@partners.org; Annekathryn Goodman: agoodman@partners.org; Bo R. \\ Rueda: brueda@partners.org \\ ${ }^{1}$ Obstetrics and Gynecology, Brigham and Women's Hospital, Boston, MA \\ ${ }^{2}$ Department of Pathology, Brigham and Women's Hospital, Boston, MA \\ ${ }^{3}$ Cancer Center, Massachusetts General Hospital, Boston, MA \\ ${ }^{4}$ Vincent Center for Reproductive Biology, Massachusetts General Hospital, Boston, MA
}

\begin{abstract}
Objective-CA125 at presentation of ovarian cancer carries important prognostic significance; but, other than tumor characteristics, little is known about factors that influence CA125 levels. We examined the effect of epidemiologic variables and tumor features on CA125 at diagnosis and their effects on survival.
\end{abstract}

Methods-CA125 levels before treatment, tumor features, and questionnaire data were recorded on 805 women with ovarian cancer receiving care at Partners Hospitals. CA125 values were lognormalized and generalized linear, logistic, or Cox proportional hazards models used to identify predictors of CA125 and influence on survival in the subset of women with invasive, non-mucinous tumors.

Results-The importance of histology, grade, stage, laterality, and presence of ascites on CA125 level was confirmed. For non-mucinous invasive cancers, Jewish ethnicity, parity, prior breast cancer, and family history of breast or ovarian cancer predicted higher CA125 and greater body mass index (BMI), recurrent yeast infections, colitis, and appendectomy predicted lower CA125. A quadratic model best described the relationship between CA125 and age with lower levels in youngest and oldest women. In multivariate modeling, stage, ascites, and prior breast cancer were the strongest predictors of high CA125 and appendectomy and yeast infections strongest predictors of low CA125. A model with these variables plus CA125 revealed high CA125 remains a predictor of poorer survival.

(C) 2010 Elsevier Inc. All rights reserved.

Correspondence: Daniel W. Cramer, M.D., Sc.D., Obstetrics, Gynecology and Reproductive Biology, Brigham and Women's Hospital, 221 Longwood Ave, Boston MA 02115, Ph: 617732 4895, Fx: 617732 4899, dcramer@partners.org.

Publisher's Disclaimer: This is a PDF file of an unedited manuscript that has been accepted for publication. As a service to our customers we are providing this early version of the manuscript. The manuscript will undergo copyediting, typesetting, and review of the resulting proof before it is published in its final citable form. Please note that during the production process errors may be discovered which could affect the content, and all legal disclaimers that apply to the journal pertain.

Conflict of interest statement

The authors declare that there are no conflicts of interest. 
Conclusions-Ovarian tumor features and presence of ascites are key determinants of CA125 at diagnosis, but epidemiologic features such as BMI, parity, prior breast cancer, and history of inflammatory conditions of the genitourinary or gastrointestinal tracts may also play a role.

\section{Introduction}

By immunizing mice with epithelial ovarian cancer cell lines and searching for antibodies that would react with patient sera, Bast and colleagues developed an assay for CA125 and found it to be elevated above $35 \mathrm{U} / \mathrm{mL}$ in about $82 \%$ of women with epithelial ovarian cancer [1]. Its kinetics during chemotherapy have value in predicting residual disease and survival [2,3] and levels after therapy can predict recurrence [4]. CA125 levels at clinical presentation are lower in women with mucinous tumors [5] and correlate directly with stage of disease and inversely with survival [6,7]. Because CA125 conveys such valuable prognostic information, it is important to understand what factors determine levels at presentation. However, other than features of the tumor, surprisingly little has been written about epidemiologic factors that predict CA125 at the time of diagnosis of ovarian cancer. In this study we sought to examine tumor characteristics as well as epidemiologic features that predict CA125 at diagnosis and how these affect the prognostic significance of CA125.

\section{Methods}

\section{Cases}

Ovarian cancer cases in this study were enrolled from one protocol that recruits patients before surgery with a pelvic mass suspicious for ovarian cancer and a second that recruits patients for a case-control study after a diagnosis has already been made. Both protocols involve informed consent and are approved by the Brigham and Women's Hospital (BWH) and Massachusetts General Hospital (MGH) (Partners) Institutional Review Boards allowing for collection of questionnaires, specimens, and review of medical records. The pelvic mass study is restricted to cases recruited from Gynecologic Oncology Clinics at MGH and the BWH/Dana Farber Cancer Institute (DFCI). Although the case-control study recruited cases from throughout Eastern Massachusetts and New Hampshire, only patients diagnosed at BWH/DFCI and MGH were included for comparability to the pelvic mass group and feasibility in retrieving CA125 laboratory values. Between 1998 and 2009, 376 cases from the pelvic mass study and 809 cases from the case-control study were enrolled from the three hospitals.

\section{Questionnaire and Medical Record Data}

Patients enrolled in the pelvic mass study completed self-administered questionnaires and those enrolled in the case-control study completed longer personally-administered questionnaires. Demographic data, reproductive history, key exposures, and medical and family history were collected. Medical records and computerized laboratory reports were reviewed to determine whether a CA125 had been obtained prior to surgery. We were able to obtain a pre-operative CA125 within 6 months of the date of diagnosis for 278 (74\%) of the pelvic mass cases and $555(69 \%)$ of the case-control cases. We excluded 28 cases who had neo-adjuvant chemotherapy before CA125 was measured, leaving 805 cases as the basis for this report. Details from the pathology report were abstracted including histologic type, stage, grade, and laterality of disease. Presence of ascites and its volume at initial diagnosis were recorded from the operative note or pre-operative imaging. Date of death was obtained from the chart or querying the Social Security Death Index.

\section{Statistical Analysis}

CA125 levels were log normalized. Means and confidence intervals (CI) were calculated on the log scale and exponentiated back to U/mL. Statistical analyses involved logistic regression 
models with CA125 at presentation dichotomized into high and low or generalized linear models with continuous CA125. Additionally, we used Cox regression to examine the relationship between CA125 and survival. Estimated number of ovulatory cycles was calculated using an algorithm that included age at menopause (or current age if premenopausal), age at menarche, average cycle length, and time spent pregnant, breast-feeding, or using oral contraceptives [8].

\section{Results}

CA125 levels by enrollment features or tumor characteristics for all 805 cases are shown in Table 1. More than $90 \%$ of the cases had CA125drawn within a month of diagnosis and their levels were higher than those drawn at earlier time points. CA125 did not vary significantly by year or site of enrollment. CA125 increased significantly with both advancing tumor grade and stage of disease and varied markedly by histologic type. Lowest CA125 levels occurred with borderline tumors and invasive mucinous tumors. Invasive serous tumors were associated with the highest CA125, mean (and 95\% CI) $=553 \mathrm{U} / \mathrm{mL}(471,649)$, and clear cell,

endometrioid, mixed, and undifferentiated tumors lower levels. For cases enrolled since 2005, pathologic review has included greater effort to identify co-existing intra-epithelial tubal neoplasia suggesting serous tumors with possible Fallopian tube origin [9]. Women whose ovarian cancer was likely tubal had significantly lower CA125 compared to women with invasive serous cancer likely of ovarian origin or primary peritoneal cancer. Bilateral tumors and presence of ascites were associated with significantly higher CA125. Within each histologic subtype except mucinous, advanced-stage disease or presence of ascites predicted higher CA125 (data not shown). For the entire dataset, the average CA125 (and 95\% CI) was $259 \mathrm{U} / \mathrm{mL}(227,295)$. One standard deviation (sd) below the mean was 38 and 1 sd above the mean was 1748 , suggesting cut points of $<35$ and $>1750$ for defining groups with low and high CA125 levels.

Correlations between CA125 and continuous variables within histologic subgroups are shown in Table 2. While weak inverse linear associations with age were noted for serous borderline $(\mathrm{p}=0.03)$ and invasive serous cases $(\mathrm{p}=0.03)$, a quadratic relationship was better at defining the association in all non-mucinous invasive cases $(\mathrm{p}=0.004)$. This model predicted lower levels in younger and older women with a peak occurrence at ages 54-56 (Figure 1). There was a weak inverse correlation with years since natural menopause for all cases $(\mathrm{p}=0.04)$ which did not change much if years since hysterectomy was added. A weak inverse association was noted between body mass index (BMI) and CA 125 for all cases $(\mathrm{p}=0.11)$. A weak positive association between estimated ovulatory cycles and CA125 found only for women with endometrioid tumors $(\mathrm{p}=0.06)$. Data was too sparse to evaluate the correlation of ascites volume with CA125 within histologic subtypes but was positively correlated in women with endometrioid and serous borderline tumors $(\mathrm{r}=0.56, \mathrm{p}=0.03$ with an $\mathrm{N}$ of 15$)$.

Levels of CA125 restricted to the 636 cases with non-mucinous invasive ovarian cancers are shown in Table 3 by categorical variables. Women who were within 10 years of menopause had higher CA125 than pre-menopausal women or women >10 years from menopause, reinforcing the quadratic relationship with age described above and inverse association with years since menopause. Women with Jewish ethnic background had significantly higher CA125 levels than non-Jewish women. Treatment of BMI as a categorical variable illustrates the trend for women with higher BMI to have lower CA125. A strong association was the trend for CA125 to increase with number of children ( $p$ for trend $=0.0005$ ). Women who reported having had a tubal ligation also had higher CA125 (which did not persist after adjustment for parity). Although constituting a small group (and restricted to case-control cases who had this level of detail recorded), women who reported recurrent vaginal yeast infections or urinary tract infections had lower levels of CA125. Gastrointestinal conditions predicting lower CA125 
included history of appendectomy or colitis. Two other strong associations were that women who had a prior breast cancer before developing ovarian cancer or who had a family history of ovarian or breast cancer had significantly higher levels of CA125. Associations between lower CA125 and non-white ethnicity $(\mathrm{p}=0.06)$ and history of endometriosis $(\mathrm{p}=0.09)$ were of borderline significance.

Exclusion of cases with CA125 more remote from diagnosis or restriction to women with invasive serous tumors did not negate associations described above except the borderline association with endometriosis and low CA125. While our cutoffs were based on the CA125 distribution using all cases, choosing cutoffs for low and high based on standard deviations above and below the mean for non-mucinous invasive cases only would have led to cutoffs of 70 and $2300 \mathrm{U} / \mathrm{mL}$ but would not have changed the conclusions from Table 3 in any substantive way (data not shown).

We next assessed multivariate models for predicting CA125 levels. Because we wished to include variables collected only in the case-control study, these analyses were restricted to 427 non-mucinous invasive cases. When histologic subtype and all variables with $\mathrm{p}<0.10$ in Table 3 were inserted into a linear model, the variables shown in Table 4 remained at least borderline significance, while endometriosis, non-white race, tubal ligation, and family history of breast and ovarian cancer were dropped. Variables that remained significant predictors included yeast infections, appendectomy, personal history of breast cancer, and histology. When stage and ascites (model 2) was introduced, the significance of nearly all variables including histology decreased, although yeast infections, appendectomy, and breast cancer remained significant. Thus stage, ascites, and personal history of breast cancer were the strongest predictors of higher CA125, while appendectomy and yeast infections were the strongest predictors of lower CA125. Parity (as a continuous variable) was of borderline significance in predicting higher CA125 in model 2.

Restricting to the 427 cases used in Table 4 and beginning with the same variables as model 1 in Table 4 and adding CA125 level, we examined their joint effects on survival (Table 5). High CA125 was significantly associated with poorer survival while histologic types other than serous were associated with more favorable survival. High CA125 persisted as a significant predictor of decreased survival ( $\mathrm{p}$ for trend $=0.04$ ) although the level of significance decreased as stage and presence of ascites were added in model 2. Thus advanced stage, presence of ascites, serous histology, and higher CA125 remain predictors of poorer survival. No epidemiologic features that predicted CA125 were significant predictors of survival, although history of colitis was of borderline significance $(\mathrm{p}=0.07)$ in predicting poorer survival.

\section{Discussion}

In this study, we sought to correlate pre-treatment levels of CA125 in women with ovarian cancer with characteristics of their tumors or patients themselves. We confirmed tumor characteristics previously reported to influence CA125; highest levels in women with invasive serous tumors, intermediate levels in women with endometrioid and clear cell tumors, lowest levels in women with mucinous and borderline tumors [5,6,10-12], and positive correlations with stage and grade $[6,11]$. A new finding was that women with invasive serous tumors more likely of Fallopian tube origin had lower CA125. A multicenter study of patients with primary Fallopian tube cancers reported the average CA125 to be $183 \mathrm{U} / \mathrm{mL}$ [13] which is clearly lower than the level for all invasive serous cancers found here or reported by others [6]. Another "tumor" characteristic strongly correlated with CA125 was ascites. The presence of ascites is more likely to suggest malignancy in women with a pelvic mass [14] and correlates with higher CA125 [15]. However, it is known that ascites in non-malignant conditions such as liver failure, abdominal tuberculosis, and cardiac failure is also associated with high CA125 [16]. 
While few studies have examined how patient characteristics influence CA125, epidemiologic features predicting CA125 in women without ovarian cancer come from trials using CA125 as a screening tool in the general population, including the first UK screening trial [17] and the Prostate, Lung, Colorectal, and Ovarian (PLCO) cancer screening trial [18]. Although these studies involved CA125 mostly in the normal range in asymptomatic women while our study dealt with abnormal levels in ovarian cancer cases, we think it relevant to highlight common findings. In both studies, non-white race was associated with significantly lower CA125 levels - an association of borderline significance in our study. Since the association was not significant in multivariate analyses, confounding could underlie the association, although genetic variation in CA125 structure or expression would not be surprising. The PLCO study found, as we did, that higher BMI was associated with lower CA125, and the authors suggested that higher plasma volumes associated with obesity might dilute the CA125 concentration. This seems unlikely to explain the one-third decrease in CA125 levels going from lowest to highest BMI categories.

Personal history of breast cancer was a strong predictor of high CA125 that persisted in multivariate models. History of breast cancer in controls from the PLCO trial was also associated with significantly higher CA125 [18]; and an earlier analysis of the UK data reported an association with breast cancer history and high CA125 [19]. Of interest, a candidate for the gene for CA125 was initially thought to be one subsequently identified as NIBR1 (neighbor of BRCA1), after polyclonal antibodies against CA125 were found to react with the gene product of NIBR1 clones. This was not further studied after characteristics of NIBR1 were found not compatible with CA125 structure [20] making it unclear whether this observation relates to the breast cancer/high CA125 association.

Age as a predictor of CA125 has been examined in ovarian cancer cases as well as controls without a consensus. In postmenopausal women, the UK study reported decreasing levels with age [17] and the PLCO study increasing levels with age [18]. Our study found that the relationship between age and CA125 may vary by histologic type (Table 2); but, in all nonmucinous invasive tumors, the relationship may best be described by an inverse U-shaped association with lower levels in younger and older women. A similar relationship was described in women at hereditary risk for ovarian cancer and age-matched controls [21]. The precise relationship with age is important since it is relevant to the potential application of CA125 in general population screening.

An intriguing association is the correlation between parity and CA125. A similar relationship in postmenopausal women without ovarian cancer was reported by Westoff [22]. In our study, women who had more than 4 births had about double the level of CA125 as nulliparous women. Parity remained a significant predictor of CA125 in a multivariate model adjusted for histology, but became of borderline significance after adjustment for stage and presence of ascites. CA125 may be involved in the process of implantation [23] and is elevated during pregnancy [24]. Perhaps of greater relevance to CA125 remote from pregnancy are changes in immunologic parameters that occur with pregnancy and persist to distinguish nulliparous from parous women and parous women by number of pregnancies, especially ratios of lymphocyte subpopulations [25]. Further study regarding the association between parity and CA125 is clearly warranted.

Our study suggests that some events involving peritoneal or mucosal inflammation lead to lower CA125. History of endometriosis, which was associated with lower CA125 levels in the PLCO study [18], trended in the same direction in our study. New observations from our study are that recurrent yeast infections and history of appendectomy and colitis are associated with lower CA125 levels. That CA125 would be lower with history of these conditions is curious since active endometriosis [26], and colitis [27] are associated with elevated CA125.

Additionally, CA125 is found in very high levels in vaginal fluid and is further elevated with 
cervicitis and vaginitis [28]. To relate elevated CA125 during active disease with lower CA125 with history of these conditions, we hypothesize that spillage of CA125 during these conditions might lead to the selection of B cells that could produce antibodies against CA125. These could persist and produce anti-CA125 antibodies capable of forming immune complexes that could shield CA125 from conventional assay, as has been described for MUC1 [29]. We have reported the development of an assay that can detect CA125 bound in immune complexes that may help explain some cases of ovarian cancer with low CA125 levels [30].

Studies find high pre-operative CA125 predicts poorer survival [6,7]. We sought to determine whether CA125's inverse correlation with survival remained after including other variables that predicted CA125. Although the level of significance decreased, the trend for a higher CA125 to be associated with poorer survival persisted after adjustment for stage, presence of ascites, and key epidemiologic variables that predicted CA125.

There are several potential limitations of our study. CA125 was not standardized by time from diagnosis or laboratory (although our study dates from 1998 to 2009 during which time the CA125 II assay was in use at both hospitals). In some cases, we abstracted the CA125 level from notes whereas, in other cases, we were able to link to a computerized record of the laboratory report. The mean value (and 95\% CI) in the former group was $277(238,322)$ and not significantly different from the mean in the latter group $215(163,283), p=0.10$. Because ours is the first study to examine multiple epidemiologic features of cases in relation to CA125, chance could account for some of our findings. However, we pointed out there is support in non-cancer controls for three key findings (lower levels with BMI and higher levels with parity and history of breast cancer); and we presented our case for a biologic basis for the role of genitourinary or gastrointestinal mucosal inflammation associated with low CA125.

Although it was not feasible in our study to investigate tumor expression of CA125, there is already an understanding of tumor expression of CA125 by histologic type. Hogdall et. al. found the highest tissue expression in invasive and borderline serous cancer (85-90\%), lowest with borderline and invasive mucinous tumors (6-12\%) and intermediate in invasive clear cell and endometrioid tumors (40-65\%) [5]. Thus tissue expression seems to track with serum expression with a notable exception being invasive and borderline serous tumors. Tissue expression of CA125 is 85-90\% in both types, while the mean CA125 level is about nine fold higher in invasive compared to borderline serous tumors in our study.

In conclusion, we have examined detailed patient characteristics as predictors of CA125 in a large series of ovarian cancer cases. We found that BMI predicted lower, and parity and personal history of breast cancer higher CA125. These observations have also been made in healthy controls-important because it suggests these events are basic to the "physiology" of CA125 and not simply producing effects through the tumor. To be sure, tumor characteristics profoundly influence CA125 as illustrated by effects of histology, grade, stage, and presence of ascites. Finally, we speculated about the role of certain conditions involving peritoneal and mucosal inflammation such as endometriosis, colitis or recurrent yeast infections. A better understanding of the influence of patient characteristics on CA125 is necessary for optimal use of CA125 as a prognostic tool and possible future application to general population screening.

\section{Acknowledgments}

This work was supported by the following National Cancer Institute grants to DWC: Ovarian Cancer SPORE (P50 CA105009), R01 CA54419, and 5U01 CA86381 from the Early Detection Research Network. 


\section{References}

1. Bast RC Jr, Klug TL, St John E, Jenison E, Niloff JM, Lazarus H, Berkowitz RS, Leavitt T, Griffiths CT, Parker L, Zurawski VR Jr, Knapp RC. A radioimmunoassay using a monoclonal antibody to monitor the course of epithelial ovarian cancer. N Engl J Med 1983;309:883-887. [PubMed: 6310399]

2. Buller RE, Berman ML, Bloss JD, Manetta A, DiSaia PJ. Serum CA125 regression in epithelial ovarian cancer: correlation with reassessment findings and survival. Gynecol Oncol 1992;47:87-92. [PubMed: 1427408]

3. Gadducci A, Zola P, Landoni F, Maggino T, Sartori E, Bergamino T, Cristofani R. Serum half-life of CA 125 during early chemotherapy as an independent prognostic variable for patients with advanced epithelial ovarian cancer: results of a multicentric Italian study. Gynecol Oncol 1995;58:42-47.

[PubMed: 7789889]

4. Schilthuis MS, Aalders JG, Bouma J, Kooi H, Fleuren GJ, Willemse PH, De Bruijn HW. Serum CA 125 levels in epithelial ovarian cancer: relation with findings at second-look operations and their role in the detection of tumour recurrence. Br J Obstet Gynaecol 1987;94:202-207. [PubMed: 3471274]

5. Hogdall EV, Christensen L, Kjaer SK, Blaakaer J, Kjaerbye-Thygesen A, Gayther S, Jacobs IJ, Hogdall CK. CA125 expression pattern, prognosis and correlation with serum CA125 in ovarian tumor patients. From The Danish "MALOVA" Ovarian Cancer Study. Gynecol Oncol 2007;104:508-515. [PubMed: 17113137]

6. Cooper BC, Sood AK, Davis CS, Ritchie JM, Sorosky JI, Anderson B, Buller RE. Preoperative CA 125 levels: an independent prognostic factor for epithelial ovarian cancer. Obstet Gynecol 2002;100:59-64. [PubMed: 12100804]

7. Geisler JP, Miller GA, Lee TH, Harwood RM, Wiemann MC, Geisler HE. Relationship of preoperative serum CA-125 to survival in epithelial ovarian carcinoma. J Reprod Med 1996;41:140-142. [PubMed: 8778409]

8. Terry KL, Titus-Ernstoff L, McKolanis JR, Welch WR, Finn OJ, Cramer DW. Incessant ovulation, mucin 1 immunity, and risk for ovarian cancer. Cancer Epidemiol Biomarkers Prev 2007;16:30-35. [PubMed: 17220329]

9. Medeiros F, Muto MG, Lee Y, Elvin JA, Callahan MJ, Feltmate C, Garber JE, Cramer DW, Crum CP. The tubal fimbria is a preferred site for early adenocarcinoma in women with familial ovarian cancer syndrome. Am J Surg Pathol 2006;30:230-236. [PubMed: 16434898]

10. Kolwijck E, Thomas CM, Bulten J, Massuger LF. Preoperative CA-125 levels in 123 patients with borderline ovarian tumors: a retrospective analysis and review of the literature. Int J Gynecol Cancer 2009;19:1335-1338. [PubMed: 20009886]

11. Makar AP, Kristensen GB, Kaern J, Bormer OP, Abeler VM, Trope CG. Prognostic value of pre- and postoperative serum CA 125 levels in ovarian cancer: new aspects and multivariate analysis. Obstet Gynecol 1992;79:1002-1010. [PubMed: 1579296]

12. Zanaboni F, Vergadoro F, Presti M, Gallotti P, Lombardi F, Bolis G. Tumor antigen CA 125 as a marker of ovarian epithelial carcinoma. Gynecol Oncol 1987;28:61-67. [PubMed: 2443433]

13. Hefler LA, Rosen AC, Graf AH, Lahousen M, Klein M, Leodolter S, Reinthaller A, Kainz C, Tempfer $\mathrm{CB}$. The clinical value of serum concentrations of cancer antigen 125 in patients with primary fallopian tube carcinoma: a multicenter study. Cancer 2000;89:1555-1560. [PubMed: 11013371]

14. Shen-Gunther J, Mannel RS. Ascites as a predictor of ovarian malignancy. Gynecol Oncol 2002;87:77-83. [PubMed: 12468346]

15. Saygili U, Guclu S, Uslu T, Erten O, Dogan E. The effect of ascites, mass volume, and peritoneal carcinomatosis on serum CA125 levels in patients with ovarian carcinoma. Int J Gynecol Cancer 2002;12:438-442. [PubMed: 12366659]

16. Miralles C, Orea M, Espana P, Provencio M, Sanchez A, Cantos B, Cubedo R, Carcereny E, Bonilla $\mathrm{F}$, Gea T. Cancer antigen 125 associated with multiple benign and malignant pathologies. Ann Surg Oncol 2003;10:150-154. [PubMed: 12620910]

17. Pauler DK, Menon U, McIntosh M, Symecko HL, Skates SJ, Jacobs IJ. Factors influencing serum CA125II levels in healthy postmenopausal women. Cancer Epidemiol Biomarkers Prev 2001;10:489-493. [PubMed: 11352859] 
18. Johnson CC, Kessel B, Riley TL, Ragard LR, Williams CR, Xu JL, Buys SS. The epidemiology of CA-125 in women without evidence of ovarian cancer in the Prostate, Lung, Colorectal and Ovarian Cancer (PLCO) Screening Trial. Gynecol Oncol 2008;110:383-389. [PubMed: 18586313]

19. Jeyarajah AR, Ind TE, Skates S, Oram DH, Jacobs IJ. Serum CA125 elevation and risk of clinical detection of cancer in asymptomatic postmenopausal women. Cancer 1999;85:2068-2072. [PubMed: 10223249]

20. Chambers JA, Solomon E. Isolation of the murine Nbr1 gene adjacent to the murine Brca1 gene. Genomics 1996;38:305-313. [PubMed: 8975707]

21. Hermsen BB, von Mensdorff-Pouilly S, Berkhof J, van Diest PJ, Gille JJ, Menko FH, Blankenstein MA, Kenemans P, Verheijen RH. Serum CA-125 in relation to adnexal dysplasia and cancer in women at hereditary high risk of ovarian cancer. J Clin Oncol 2007;25:1383-1389. [PubMed: 17416858]

22. Westhoff C, Gollub E, Patel J, Rivera H, Bast R Jr. CA 125 levels in menopausal women. Obstet Gynecol 1990;76:428-431. [PubMed: 2381621]

23. Gipson IK, Blalock T, Tisdale A, Spurr-Michaud S, Allcorn S, Stavreus-Evers A, Gemzell K. MUC16 is lost from the uterodome (pinopode) surface of the receptive human endometrium: in vitro evidence that MUC16 is a barrier to trophoblast adherence. Biol Reprod 2008;78:134-142. [PubMed: 17942799]

24. Haga Y, Sakamoto K, Egami H, Yoshimura R, Akagi M. Evaluation of serum CA125 values in healthy individuals and pregnant women. Am J Med Sci 1986;292:25-29. [PubMed: 3521278]

25. Komlos L, Landmann J, Notmann J, Aloni D, Dulitzky F, Goldman J, Halbrecht I. Lymphocyte subpopulations in mother and newborn: correlation with sex of the newborn and number of pregnancies. Gynecol Obstet Invest 1989;27:143-147. [PubMed: 2661359]

26. Muyldermans M, Cornillie F, Koninckx P. CA125 and endometriosis Human Reproduction Update 1995;1:173-187.

27. Ataseven H, Ozturk Z, Arhan M, HYuksel O, Koklu S, Ibis M, Basar O, Yilmaz F, Yuksel I. Cancer antigen 125 levels in inflammatory bowel diseases. Journal of Clinical Laboratory Analysis 2009;23:24408.

28. Sarandakou A, Phocas I, Botsis D, Rizos D, Trakakis E, Chryssikopoulos A. Vaginal fluid and serum CEA, CA125 and SCC in normal conditions and in benign and malignant diseases of the genital tract. Acta Oncol 1997;36:755-759. [PubMed: 9490096]

29. Gourevitch MM, von Mensdorff-Pouilly S, Litvinov SV, Kenemans P, van Kamp GJ, Verstraeten AA, Hilgers J. Polymorphic epithelial mucin (MUC-1)-containing circulating immune complexes in carcinoma patients. Br J Cancer 1995;72:934-938. [PubMed: 7547243]

30. O'Rourke DJ, DiJohnson DA, Vitonis AF, Cramer DW, Liu BCS. Autoantibody Signatures and Immune Complexes as Potential Biomarkers in Ovarian Cancer with Low Serum CA-125. Clinical Chemistry 2010;56:A196. 


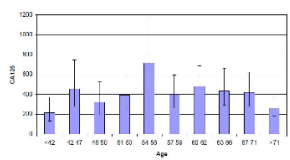

Figure 1.

Geometric mean CA125 by age in non-mucinous invasive cases illustrating inverse $\mathrm{U}$ (quadratic) association. 
Table 1

Geometric mean pre-operative CA125 levels by enrollment and tumor characteristics.

\begin{tabular}{|c|c|c|c|}
\hline Characteristic & $\mathbf{N}(\%)$ & CA125 geometric mean $(95 \%$ CI) & p-value $*$ \\
\hline \multicolumn{4}{|l|}{ Timing of CA125 prior to diagnosis } \\
\hline$<30$ days & $748(92.9 \%)$ & $279(244,320)$ & \\
\hline $30-180$ days & $57(7.1 \%)$ & $97(60,159)$ & $<0.0001$ \\
\hline \multicolumn{4}{|l|}{ Study } \\
\hline Pelvic Mass & $268(33.3 \%)$ & $302(240,379)$ & \\
\hline Case-controls & $537(66.7 \%)$ & $240(204,282)$ & 0.11 \\
\hline \multicolumn{4}{|l|}{ Year of enrollment } \\
\hline 1998-2001 & $152(18.9 \%)$ & $236(174,319)$ & \\
\hline 2002-2004 & $282(35.0 \%)$ & $288(230,360)$ & \\
\hline $2005-2006$ & $162(20.1 \%)$ & $269(200,361)$ & \\
\hline 2007-2009 & $209(26.0 \%)$ & $235(181,304)$ & 0.71 \\
\hline \multicolumn{4}{|l|}{ Site of enrollment } \\
\hline Brigham and Women's Hospital & $516(64.1 \%)$ & $255(216,301)$ & \\
\hline Massachusetts General Hospital & $289(35.9 \%)$ & $266(214,332)$ & 0.76 \\
\hline \multicolumn{4}{|l|}{ Grade } \\
\hline Borderline & $138(17.3 \%)$ & $47(35,62)$ & $<0.0001$ \\
\hline Well differentiated & $66(8.3 \%)$ & $118(79,177)$ & $<0.0001$ \\
\hline Moderately differentiated & $111(13.9 \%)$ & $270(198,370)$ & 0.0003 \\
\hline Poorly differentiated & $435(54.5 \%)$ & $517(441,605)$ & Ref \\
\hline Ungraded & $48(6.0 \%)$ & $163(101,262)$ & $<0.0001$ \\
\hline \multicolumn{4}{|l|}{ Stage } \\
\hline I & $249(31.3 \%)$ & $57(47,70)$ & Ref \\
\hline II & $64(8.1 \%)$ & $192(131,282)$ & $<0.0001$ \\
\hline III & $430(54.1 \%)$ & $543(468,630)$ & $<0.0001$ \\
\hline IV & $52(6.5 \%)$ & $1204(786,1846)$ & $<0.0001$ \\
\hline \multicolumn{4}{|l|}{ Histology } \\
\hline Serous borderline & $84(10.4 \%)$ & $61(43,86)$ & $<0.0001$ \\
\hline Mucinous borderline & $40(5.0 \%)$ & $28(17,46)$ & $<0.0001$ \\
\hline Other borderline & $14(1.7 \%)$ & $43(18,102)$ & $<0.0001$ \\
\hline Serous invasive & $407(50.6 \%)$ & $553(471,649)$ & Ref \\
\hline Mucinous invasive & $31(3.8 \%)$ & $60(33,106)$ & $<0.0001$ \\
\hline Clear cell & $35(4.4 \%)$ & $114(66,197)$ & $<0.0001$ \\
\hline Endometrioid & $92(11.4 \%)$ & $197(141,276)$ & $<0.0001$ \\
\hline Mixed/other/undifferentiated & $102(12.7 \%)$ & $341(247,469)$ & 0.008 \\
\hline \multicolumn{4}{|l|}{ Subset of cases with information } \\
\hline \multicolumn{4}{|l|}{ on possible tubal origin } \\
\hline Serous invasive & $256(83.1 \%)$ & $590(484,720)$ & Ref \\
\hline Primary peritoneal & $15(4.9 \%)$ & $1133(497,2579)$ & 0.13 \\
\hline Fallopian ${ }^{\dagger}$ & $37(12.0 \%)$ & $197(117,333)$ & 0.0002 \\
\hline
\end{tabular}




\begin{tabular}{lccc}
\hline Characteristic & N $(\%)$ & CA125 geometric mean $(\mathbf{9 5 \%}$ CI) & p-value \\
\hline Ascites & & & \\
None & $383(47.6 \%)$ & $88(75,103)$ & Ref \\
$<1200 \mathrm{cc}$ & $73(9.1 \%)$ & $598(416,859)$ & $<0.0001$ \\
$1200-3000 \mathrm{cc}$ & $86(10.7 \%)$ & $1326(950,1851)$ & $<0.0001$ \\
$>3000 \mathrm{cc}$ & $74(9.2 \%)$ & $1030(719,1475)$ & $<0.0001$ \\
Unknown amount & $188(23.4 \%)$ & $471(376,590)$ & $<0.0001$ \\
Laterality & & & \\
Unilateral & $277(38.3 \%)$ & $82(67,100)$ & \\
Bilateral & $446(61.7 \%)$ & $513(438,600)$ & $<0.0001$ \\
All & 805 & $259(227,295)$ & \\
All non-mucinous invasive & 636 & $404(352,463)$ & \\
\hline
\end{tabular}

* P-value from linear regression with log-transformed CA125 as the dependent variable. With the exception of moderately differentiated grade and clear cell, endometrioid, and mixed/other/undifferentiated histologic types, all associations remained significant after adjusting for stage.

${ }^{\dagger}$ Based on detailed pathologic review showing co-existing intraepithelial tubal neoplasia. 


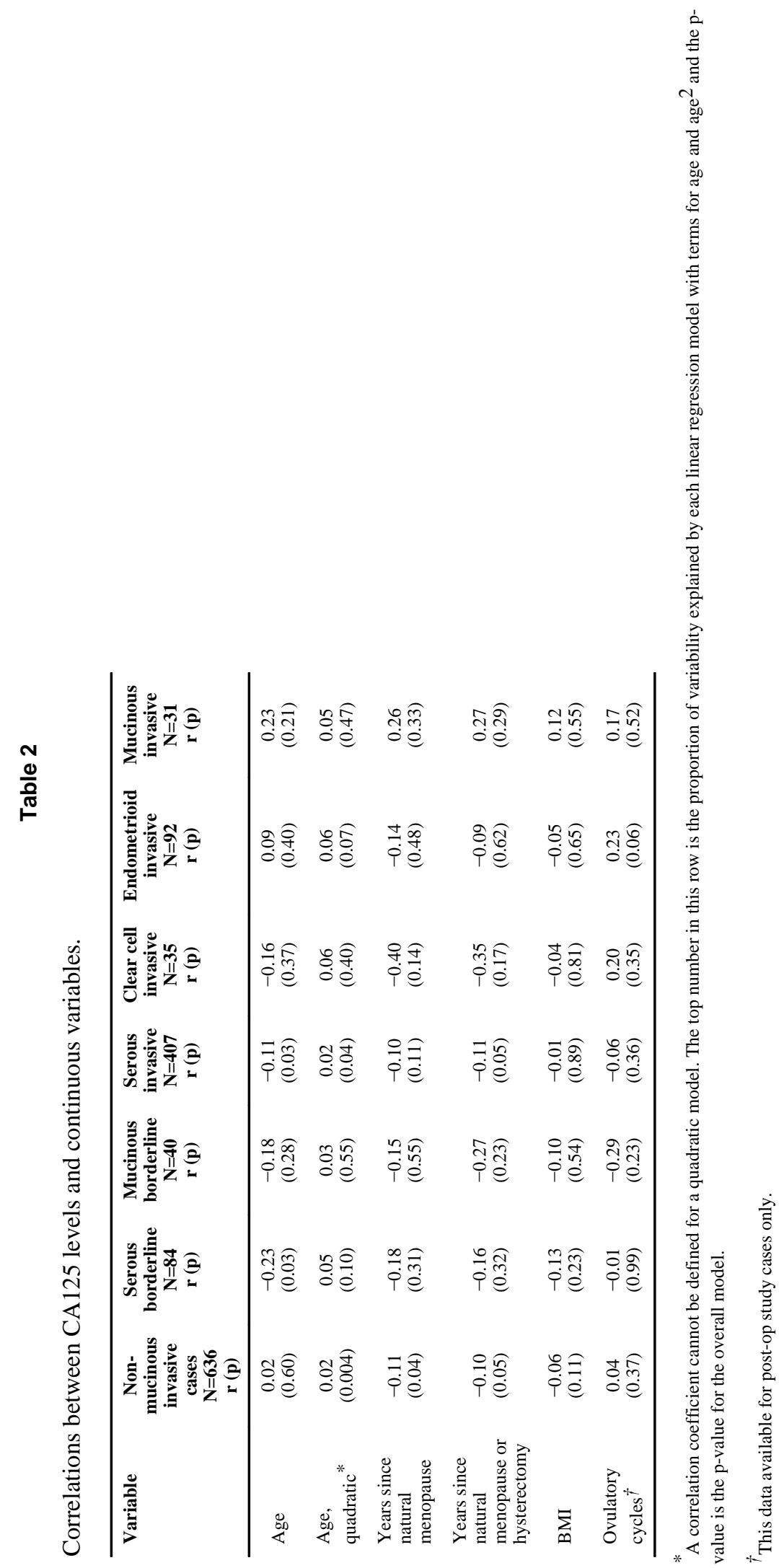




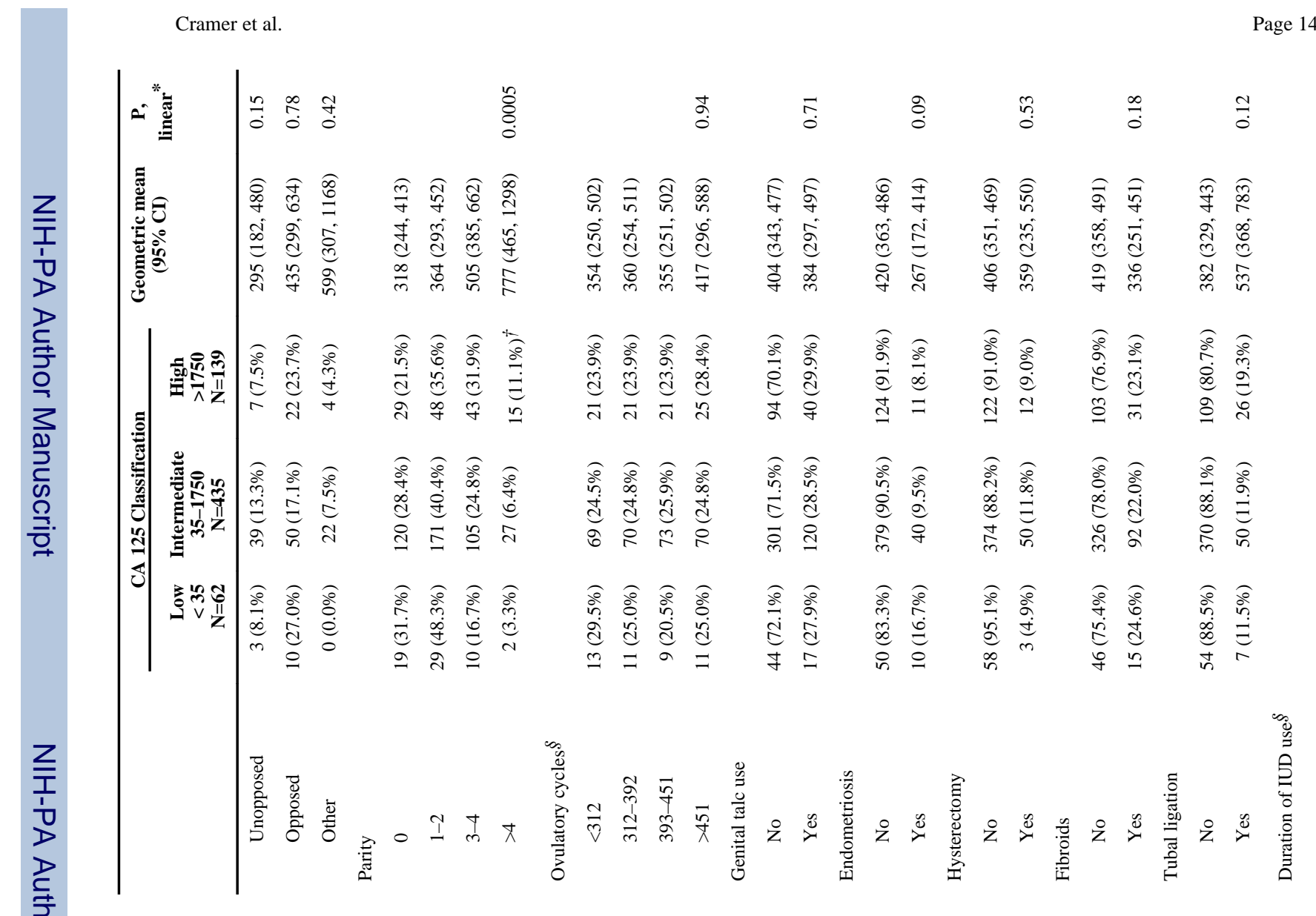

Gynecol Oncol. Author manuscript; available in PMC 2011 December 1. 
Table 4

Multivariate linear models for CA125 prediction among non-mucinous invasive post-op study cases.

\begin{tabular}{lcccc}
\hline & \multicolumn{2}{c}{ Model 1 } & \multicolumn{2}{c}{ Model 2 } \\
\cline { 2 - 5 } & Estimate & p-value & Estimate & p-value \\
\hline Age (years) & 0.13 & 0.04 & 0.06 & 0.26 \\
Age (years), squared & -0.001 & 0.04 & -0.001 & 0.24 \\
Jewish & 0.45 & 0.07 & 0.37 & 0.09 \\
BMI (quintiles) & -0.03 & 0.06 & -0.02 & 0.09 \\
Parity (continuous) & 0.14 & 0.01 & 0.09 & 0.07 \\
Yeast infections & -1.62 & 0.02 & -1.49 & 0.01 \\
Appendectomy & -0.45 & 0.03 & -0.50 & 0.008 \\
Colitis & -1.03 & 0.07 & -0.65 & 0.19 \\
History of breast cancer & 0.88 & 0.004 & 0.87 & 0.002 \\
Endometrioid/clear cell (vs. serous) & -0.94 & $<0.0001$ & 0.02 & 0.91 \\
Mixed/other/undifferentiated (vs. serous) & -0.40 & 0.07 & -0.08 & 0.68 \\
Stage 3-4 (vs. 1-2) & & & 0.80 & $<0.0001$ \\
Ascites (any vs. none) & & & 1.36 & $<0.0001$ \\
\hline
\end{tabular}


Table 5

Multivariate Cox proportional hazards models for survival among non-mucinous invasive post-op study cases.

\begin{tabular}{|c|c|c|c|c|}
\hline & \multicolumn{2}{|c|}{ Model 1} & \multicolumn{2}{|l|}{ Model 2} \\
\hline & HR $(95 \%$ CI $)$ & $\mathbf{p}$ & HR $(95 \%$ CI $)$ & $\mathbf{p}$ \\
\hline CA125 35-1750 (vs. <35) & $2.64(1.15,6.10)$ & 0.02 & $1.37(0.57,3.29)$ & 0.48 \\
\hline CA125 >1750 (vs. <35) & $4.33(1.81,10.4)$ & 0.001 & $1.92(0.76,4.85)$ & 0.17 \\
\hline p-trend for CA125 categories above ${ }^{*}$ & & $<0.0001$ & & 0.04 \\
\hline Age (years) & $1.04(0.88,1.23)$ & 0.61 & $1.00(0.84,1.18)$ & 0.97 \\
\hline Age (years), squared & $1.00(1.00,1.00)$ & 0.74 & $1.00(1.00,1.00)$ & 0.79 \\
\hline Jewish & $1.02(0.66,1.58)$ & 0.94 & $0.92(0.59,1.44)$ & 0.73 \\
\hline BMI (quintiles) & $1.01(0.97,1.04)$ & 0.80 & $1.01(0.97,1.04)$ & 0.72 \\
\hline Parity (continuous) & $1.04(0.94,1.15)$ & 0.49 & $1.00(0.90,1.11)$ & 0.99 \\
\hline Yeast infections & $1.39(0.19,10.4)$ & 0.75 & $1.17(0.16,8.68)$ & 0.88 \\
\hline Appendectomy & $0.81(0.54,1.24)$ & 0.33 & $0.75(0.49,1.14)$ & 0.18 \\
\hline Colitis & $2.09(0.75,5.78)$ & 0.16 & $2.53(0.91,7.04)$ & 0.07 \\
\hline History of breast cancer & $1.03(0.59,1.79)$ & 0.93 & $1.06(0.61,1.86)$ & 0.83 \\
\hline Endometrioid/clear cell (vs. serous) & $0.18(0.09,0.37)$ & $<0.0001$ & $0.35(0.16,0.76)$ & 0.008 \\
\hline Mixed/other/Undiff. (vs. serous) & $0.52(0.32,0.83)$ & 0.006 & $0.54(0.33,0.86)$ & 0.01 \\
\hline Stage 3-4 (vs. 1-2) & & & $2.57(1.48,4.47)$ & 0.0008 \\
\hline Ascites (any vs. none) & & & $1.99(1.32,3.01)$ & 0.001 \\
\hline
\end{tabular}

